\title{
Intracranial amelanotic melanoma: a case report with literature review
}

\author{
Jun Ma, Zhong Zhang, Shu Li, Xiaolin Chen and Shuo Wang*
}

\begin{abstract}
Background: The incidence of primary central nervous system (CNS) melanocytic neoplasms is relatively low comparing to systemic ones. The performance of the tumor is variable. With poor clinical experience, the diagnosis and treatment of such tumors present to be a challenge. Amelanotic melanoma is an especially rare subtype. Only several cases have been reported.

Case presentation: We report a case of intracranial amelanotic melanoma. Preoperative assessment revealed progressive right frontal mass. The patient underwent tumor resection. The pathologic analysis reported amelanotic melanoma of intermediate grade. The further examination of the whole brain and body was negative. The familial history was also negative. The patient recovered uneventfully and went on for radiotherapy and chemotherapy. After a follow-up period of 5 months, the patient was tumor-free.

Conclusions: This is the second report about primary CNS amelanotic melanoma. We summarized characteristics of the primary CNS melanocytic lesions and amelanotic melanoma with review of the literature and review of cases of our department.
\end{abstract}

Keywords: Central nervous system, Intracranial, Primary, Melanocytic lesion, Amelanotic melanoma

\section{Background}

Primary melanocytic neoplasms of the central nervous system (CNS) belong to the tumors of the meninges. The incidence is less than $0.1 \%$. Some may relate to certain neurocutaneous syndrome. The tumor can affect the entire CNS, with miscellaneous performances. The diagnosis is always difficult before the pathology result is available. And due to the potential of malignant transformation and dissemination, the identification of the original loci is even harder. So the clinical diagnosis and treatment must base on an overall evaluation of a patient. Primary amelanotic melanoma is a special subtype of the melanocytic neoplasm, which is especially rare. We want to share our experiences of primary CNS melanocytic neoplasms and amelanotic melanoma through our cases with review of the literature.

* Correspondence: captain9858@vip.sina.com

Department of Neurosurgery, Beijing Tiantan Hospital affiliated to Capital Medical University, China National Clinical Research Center for Neurological Diseases, Center of Brain Tumor, Beijing Institute for Brain Disorders and Beijing Key Laboratory of Brian Tumor, Beijing 100050, China

\section{Case presentation Medical history}

A 64-year-old man presented to our department in December 2013 for progressive right frontal mass with dull aching for 9 months. His medical history was unremarkable except for 2 years of hypertension. The familial history was negative, with no neurocutaneous system disorders of the first grade relatives.

\section{Clinical examination}

The vital signs were stable. A mass at the right frontal region could be palpated, about $5 \mathrm{~cm}$ in diameter, hard, fixed, with no obviously red, swollen, or tender of the superficial scalp.

\section{Imaging studies}

Cranial CT scan showed an mixed iso-/hyperdensity mass in the right frontal cranial bone, about 60 to $198 \mathrm{Hu}$, measuring $34 \times 21 \mathrm{~mm}$, with clear margin. The peripheral bone appeared destructive absorption. The MR was contraindicated for metal implant (Figure 1). 

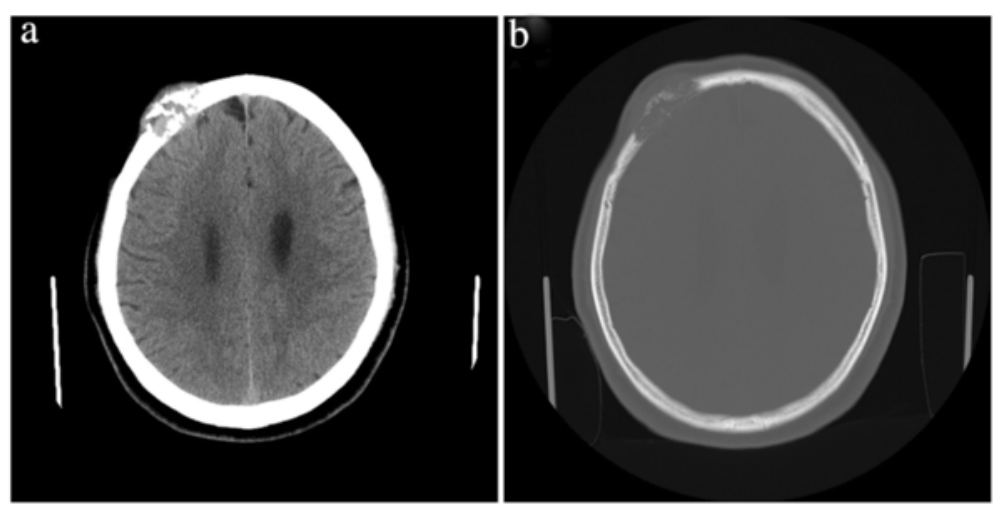

Figure 1 Preoperative CT scan of the patient. The lesion locates in the right frontal bone, isointense on $C T$ scan, with prominent bone destruction. (a) CT scan of the soft tissue. (b) CT scan of the cranial bone.

\section{Surgery, pathologic result, and postoperative course}

The patient underwent total tumor resection through right frontal approach on 24 December, 2013. The tumor eroded both the external and internal lamina of the cranial bone. The tumor was solid, soft, tender, pale white, rich blood supplied, and was adhesive to the underlying dura mater. The dura mater was yet intact, sparing the parenchyma of the cortex. The intraoperative rapid frost pathologic examination revealed malignant changes, and so after tumor resection, the adjacent dura mater was removed as well which was reconstructed with self aponeurosis. The peripheral bone was resected to the negative zone. The excision margin was about $2 \mathrm{~cm}$.

The pathologic examination reported amelanotic melanoma of intermediate grade, with positive of HMB45, MelanA (sparsely), S-100, Vimentin, CD99, SMA (sparsely), and CD34, and negative of CK, EMA, CEA, CK5/6, CK8/ 18, TTF-1, SYN, CD56, CgA, Desmin, MyoD1, TFE3, PAS, and PR. The Ki-67 was $20 \%$ to $30 \%$ ( \pm ) (Figure 2 ).

The further examination includes CT scan of the chest, abdominal, and the pelvic region and the PET scan of the whole brain and body, which were all negative.

The patient was discharged 3 days after the operation with no complications and went on for adjuvant radiotherapy and chemotherapy (concomitant stereotactic radiosurgery + ipilimumab). For more than 5 months of follow-up, the patient recovers well with no recurrence or related sequelae.

\section{Review of cases and literature}

We summarized the CNS melanocytic lesions of our neurosurgery department since 2008. Then we used the search engine of PubMed with keywords of melanoma or melanomatosis or melanocytoma or melanocytosis, and CNS and primary and further searched with keywords of CNS or brain or cranial or spinal, and amelanotic.

Thirty-two cases of CNS melanocytic lesions of our department were defined since 2008. Forty-three English reports of CNS melanocytic lesions and 14 reports about CNS amelanotic melanoma were searched. The details were summarized in the tables (Tables 1, 2, and 3).

\section{Discussion}

Primary melanocytic neoplasms of the CNS belong to the tumors of the meninges, further classified as diffuse melanocytosis, melanocytoma, malignant melanoma, and meningeal melanomatosis. The incidence is $0.06 \%$ to $0.1 \%$ of melanocytoma and $0.005 / 100,000$ of melanoma. Other subtypes are rare. There is a slight female predisposition, with the ratio of $\mathrm{F}: \mathrm{M}=1.5: 1$. The age range of melanocytoma is 9 to 73 years, most frequently from 45 to 50 years, and of the primary nodular melanoma is 15 to 71 years, averaging 43 years. The symptoms and signs are secondary to either the local effects on the CNS parenchyma or the accompanying hydrocephalus. The rapid progress with increasing ICP resulting in irritability, vomiting, lethargy, seizures, and so on may suggest malignant transformation. The diagnosis of melanocytic lesions relies on the histopathological examination. Most benign and malignant melanocytic lesions display melanin pigment distributed within tumor cells, tumor stroma, and the cytoplasm of tumoral macrophages (melanophages). Tumor with CNS invasion or elevated mitotic activity is classified as intermediate grade melanocytic neoplasms. Malignant melanoma is more pleomorphic, has more anaplastic nuclei, higher cell density, and unequivocal invasion or coagulative necrosis. Rare melanocytomas and occasional primary melanomas will not demonstrate melanin pigment, complying with 'amelanotic' Amelanotic melanoma may arise from normal melanoma with amelanotic transformation or detergent of the tumor cell. Histopathological and immunohistochemistry examinations are highly sensitive to amelanotic melanoma. The neuroimaging performance depends on the content of melanin. Isiklar et al. [1] classified the MR performance into four groups: a) The melanotic group, 

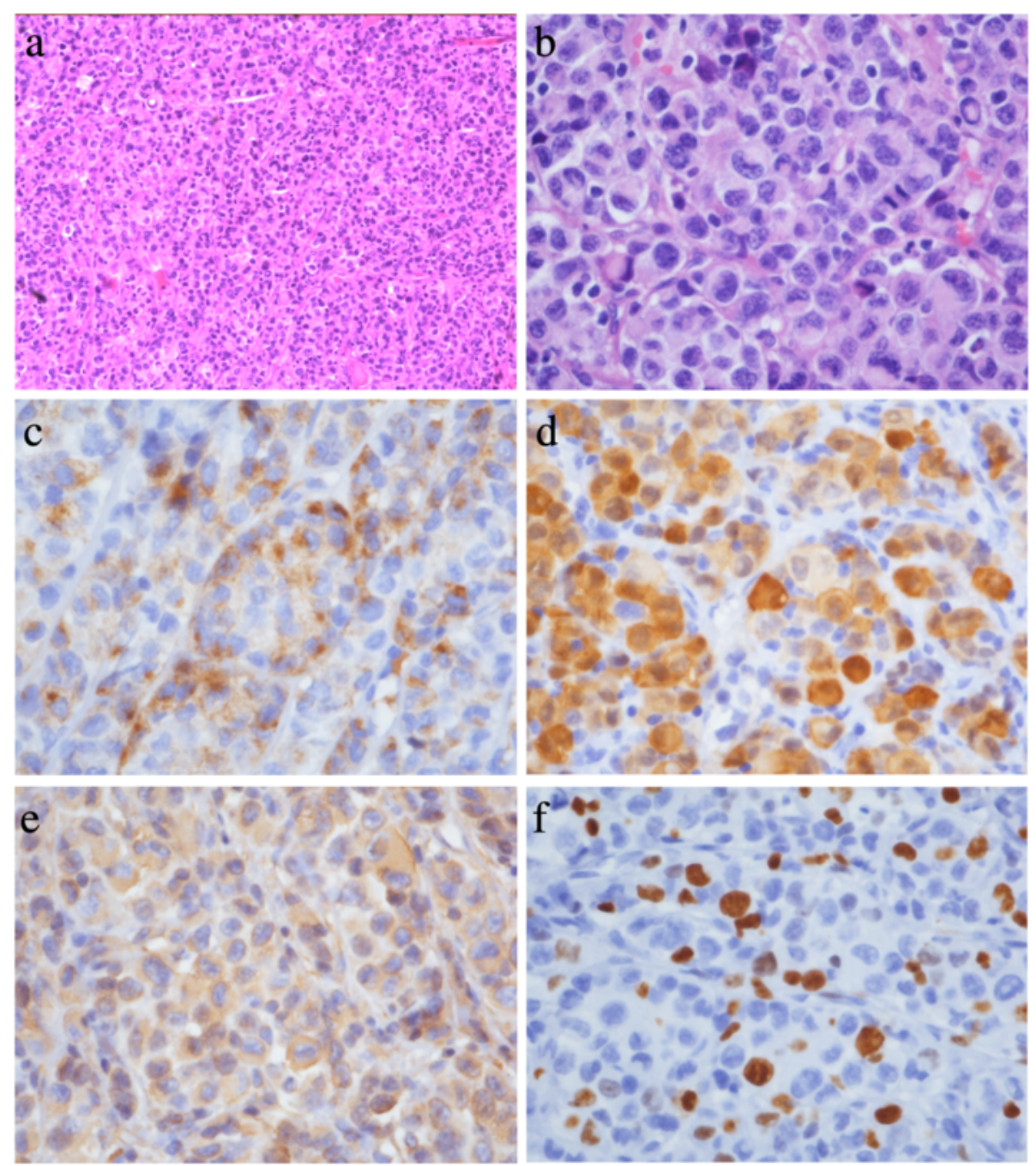

Figure 2 Pathologic results. (a) Pathology slice (hematoxylin-eosin stain, original magnification $\times 100$ ) of the tumor. Nests of intermediate-grade tumor cells with intervening stroma can be seen. The tumor cells show clear to eosinophilic cytoplasm, with no obvious pigment. (b) Higher magnification (hematoxylin-eosin stain, original magnification $\times 400$ ) of the tumor, showing prominent nuclear mitosis and atypia. (c) Higher magnification (original magnification $\times 400$ ) of the tumor, showing HMB45 positive. (d) Higher magnification (original magnification $\times 400$ ) of the tumor, showing S-100 positive. (e) Higher magnification (original magnification $\times 400$ ) of the tumor, showing Vimentin-positive. (f) Higher magnification (original magnification $\times 400$ ) of the tumor, showing Ki-67 index, was $20 \%$ to $30 \%$.

with hyperintense on T1 and hypointense on T2. b) The amelanotic group, with iso-/hypointense on T1 and iso-/ hyperintense on T2. c) The mixed group, suiting neither the two criteria. d) The hemorrhagic group, with characteristics of intra-/peri-tumoral hemorrhage. Gaviani et al. [2] reported that the T1 signal has positive correlation with the content of melanin, while T2 signal has no such correlation but is more sensitive to tiny loci.

Early in 1980s, Willis et al. pointed out that the diagnosis of 'primary' has to meet three critical conditions: a) The skin or eyeballs are negative of melanoma. b) The skin or eyeballs have no history of melanoma resection. c) The internal organs are negative of metastasis of melanoma. Savitz [3] thought that the systemic melanocytic lesions are very likely to metastases to CNS while the primary loci are quite indolent. Winkelman et al. [4] reported that $44 \%$ of all melanocytic lesions have CNS metastasis at autopsy, so that the 'primary' can only be confirmed after autopsy. So every melanocytic neoplasm may be a systemic disease, and the 'primary CNS melanocytic lesion' is just a subtype with CNS as the single manifestation clinically. There are approximately more than 60 papers describing primary CNS melanocytic lesions, with about 40 are in English, dated from 1972 to 2013. The number of cases ranged from one to ten. The symptoms are various according to the location of the tumor and so are the neuroimaging performance relating to the content of the melanin, as mentioned before. About 14 papers referred to CNS amelanotic 
Table 1 Summary of CNS melanocytic lesions of our neurosurgery department since 2008

\begin{tabular}{|c|c|c|c|c|c|}
\hline Case & Gender & $\begin{array}{l}\text { Age } \\
\text { (yr.) }\end{array}$ & Location & Pathology diagnosis & Preoperative differentiation $^{a}$ \\
\hline 1 & M & 46 & Left temporal & Intermediate-grade melanocytic tumor & - \\
\hline 2 & M & 11 & Right temporal & Malignant melanoma & - \\
\hline 3 & M & 45 & Right frontal & Malignant melanoma & Metastasis? Lymphoma? \\
\hline 4 & $\mathrm{~F}$ & 26 & Right parasellar & Malignant melanoma & Schwannoma? \\
\hline 5 & $\mathrm{~F}$ & 52 & Left frontal & Metastatic melanoma & - \\
\hline 6 & M & 43 & Right temporal & Meningeal melanomatosis & $\begin{array}{l}\text { Metastasis? Pleomorphic } \\
\text { xanthoastrocytoma? }\end{array}$ \\
\hline 7 & M & 47 & Right CPA & Meningeal melanomatosis & $\begin{array}{l}\text { Epidermoid cyst? Cavernous } \\
\text { hemangioma? }\end{array}$ \\
\hline 8 & M & 24 & Right lateral ventricle & Amelanotic melanoma? & - \\
\hline 9 & $\mathrm{~F}$ & 19 & Left parietal & Melanocytoma & Meningioma? \\
\hline 10 & $\mathrm{~F}$ & 21 & Right frontal, para-falx & Recurrent melanocytoma, with subarachnoid dissemination & Recurrent melanocytoma \\
\hline 11 & M & 38 & Right petrosal & Meningeal melanomatosis & Schwannoma? \\
\hline 12 & M & 61 & Multiple & Melanocytoma with meningeal melanomatosis & Melanoma? Metastasis? \\
\hline 13 & M & 20 & Left temporal & Malignant melanoma & - \\
\hline 14 & M & 24 & Right cerebellar & Malignant melanoma & Cyst? \\
\hline 15 & M & 47 & Foreman magnum & Malignant melanoma, with bone invasion & Meningioma? Melanoma? \\
\hline 16 & M & 47 & Left middle fossa & Malignant melanoma & $\begin{array}{l}\text { Hemangiopericytoma? } \\
\text { Meningioma? Melanoma? }\end{array}$ \\
\hline 17 & M & 45 & $\begin{array}{l}\text { Intradural extramedullary, } \\
\text { C2-T1 }\end{array}$ & Melanocytoma & Melanoma? Meningioma? \\
\hline 18 & M & 31 & Right cavernous sinus & Melanocytoma & $\begin{array}{l}\text { Melanoma? Cavernous } \\
\text { hemangioma? Aneurysm? }\end{array}$ \\
\hline 19 & M & 46 & Right middle fossa & Malignant melanoma, with bone and dura invasion & Meningioma? \\
\hline 20 & M & 20 & Left pons & Malignant melanoma & Glioma? Meningioma? \\
\hline 21 & $\mathrm{~F}$ & 41 & Multiple, T6-L1 & Melanocytoma & Neurofibrosis? \\
\hline 22 & $\mathrm{~F}$ & 28 & Right parietal occipital & Malignant melanoma, with subarachnoid dissemination & - \\
\hline 23 & $\mathrm{~F}$ & 66 & Left frontal & Malignant melanoma & - \\
\hline 24 & M & 27 & $\begin{array}{l}\text { Right interspinous } \\
\text { foramen, } \mathrm{C6}\end{array}$ & Melanocytoma & Melanoma? \\
\hline 25 & M & 39 & Foramen magnum - C2 & Melanocytoma & Lipoma? \\
\hline 26 & M & 36 & Right frontal & $\begin{array}{l}\text { Melanocytoma, with subarachnoid dissemination and } \\
\text { parenchyma invasion }\end{array}$ & Melanoma? Lymphoma? \\
\hline 27 & M & 49 & Right cerebellar tentorium & Meningeal melanomatosis & Meningioma? \\
\hline 28 & M & 17 & Left parasallar - CPA & Melanocytoma & Epidermoid cyst? \\
\hline 29 & M & 26 & Medulla & Intermediate grade melanocytic tumor & - \\
\hline 30 & M & 13 & Right cerebellar tentorium & Malignant melanoma & $\begin{array}{l}\text { Meningioma? } \\
\text { Hemangiopericytoma? }\end{array}$ \\
\hline 31 & M & 47 & Left temporal & Malignant melanoma & - \\
\hline 32 & M & 64 & Right frontal bone & Amelanotic melanoma, with bone invasion & $\begin{array}{l}\text { Eosinophilic granuloma? } \\
\text { Giant cell osteoma? Metastasis? }\end{array}$ \\
\hline
\end{tabular}

M, male; F, female, yr., years old. ${ }^{a}$ With no clear preoperative diagnosis.

melanoma, from 1981 to 2012. Most are case reports, including two primary intraspinal and two primary meningeal amelanotic melanoma, 22 intracerebral metastasis, one intraventricular metastasis, and three cases with no details. Schuknecht et al. [5] reported two primary meningeal amelanotic melanoma in 1990, serving as the only paper describing primary CNS amelanotic melanoma. There are totally 32 primary or metastatic CNS melanocytic 
Table 2 Review of the English literature of CNS melanocytic lesions

\begin{tabular}{|c|c|c|c|c|c|}
\hline Author & Year & $\mathrm{Nb}$ & Primary/metastatic ${ }^{a}$ & Diagnosis & Other \\
\hline Foit et al. & 2013 & 1 & Primary & Melanocytoma & - \\
\hline Lee et al. & 2013 & 1 & Primary & $\begin{array}{l}\text { Meningeal } \\
\text { melanomatosis }\end{array}$ & - \\
\hline Schneider et al. & 2013 & 1 & Primary & Malignant melanoma & - \\
\hline Reddy et al. & 2012 & 1 & - & Melanocytoma & - \\
\hline Sutton et al. & 2011 & 1 & - & $\begin{array}{l}\text { Leptomeningeal } \\
\text { melanocytosis }\end{array}$ & $\begin{array}{l}\text { The patient was suspected to represent a case of } \\
\text { former fruste neurocutaneous melanosis. }\end{array}$ \\
\hline Brunsvig et al. & & 1 & - & $\begin{array}{l}\text { Meningeal } \\
\text { melanocytosis }\end{array}$ & - \\
\hline Vij et al. & 2010 & 1 & Primary & Melanoma & - \\
\hline Perrini et al. & 2010 & 1 & Primary & Malignant melanoma & - \\
\hline Zadro et al. & 2010 & 1 & Primary & $\begin{array}{l}\text { Diffuse meningeal } \\
\text { melanomatosis }\end{array}$ & - \\
\hline Nishihara et al. & 2009 & 1 & Primary & Malignant melanoma & - \\
\hline Navas et al. & 2009 & 1 & - & $\begin{array}{l}\text { Meningeal } \\
\text { melanocytoma }\end{array}$ & Associated with a congenital nevus of Ota \\
\hline Holfort et al. & 2009 & 16 & Metastatic & Melanoma & $\begin{array}{l}\text { Out of review of primary uveal melanoma } 2365 \\
\text { patients }\end{array}$ \\
\hline Mathai et al. & 2008 & 1 & - & $\begin{array}{l}\text { Intermediate grade } \\
\text { meningeal } \\
\text { melanocytoma }\end{array}$ & - \\
\hline Tandon et al. & 2008 & 1 & Primary & Melanocytoma & - \\
\hline Levidou et al. & 2007 & 2 & Unknown primary site & $\begin{array}{l}\text { Leptomeningeal } \\
\text { melanoma }\end{array}$ & - \\
\hline Cajaiba et al. & 2008 & 2 & Primary & $\begin{array}{l}\text { Neurocutaneous } \\
\text { melanosis with CNS } \\
\text { melanocytoma }\end{array}$ & $\begin{array}{l}\text { Disseminated to the peritoneal surface by } \\
\text { ventriculo-peritoneal }(V-P) \text { shunt system }\end{array}$ \\
\hline Mekni et al. & 2007 & 5 & Primary & Malignant melanoma & - \\
\hline Denaro et al. & 2007 & 1 & Primary & Melanoma & - \\
\hline Bookland et al. & 2007 & 1 & Primary & Malignant melanoma & - \\
\hline Kiecker et al. & 2007 & 1 & Primary & $\begin{array}{l}\text { Neurocutaneous } \\
\text { melanosis with } \\
\text { meningeal melanoma }\end{array}$ & - \\
\hline Oluigbo et al. & 2006 & 1 & Primary & Malignant melanoma & - \\
\hline Chen & 2003 & 1 & - & $\begin{array}{l}\text { Meningeal } \\
\text { melanocytoma }\end{array}$ & - \\
\hline Classen et al. & 2002 & 1 & - & Melanocytoma & - \\
\hline Rivers et al. & 2001 & 1 & Primary & Dural melanoma & $\begin{array}{l}\text { In association with ocular melanosis and multiple } \\
\text { cutaneous blue nevi }\end{array}$ \\
\hline Greco Crasto et al. & 2001 & 1 & Primary & Melanoma & - \\
\hline Whinney et al. & 2001 & 1 & Primary & Malignant melanoma & - \\
\hline Kobayashi et al. & 2001 & 1 & - & Malignant melanoma & - \\
\hline Fathallah-Shaykh et al. & 1996 & 1 & Primary & $\begin{array}{l}\text { Leptomeningeal } \\
\text { melanoma }\end{array}$ & - \\
\hline Eaves et al. & 1995 & 1 & Primary & $\begin{array}{l}\text { Melanoma without } \\
\text { diffuse leptomeningeal } \\
\text { involvement }\end{array}$ & A variant of neurocutaneous melanosis \\
\hline Rubino et al. & 1993 & 1 & Primary & Melanoma & - \\
\hline Drake et al. & 1993 & 8 & Primary & $\begin{array}{l}\text { Malignant melanoma } \\
\text { of the leptomeninges }\end{array}$ & - \\
\hline Singhal et al. & 1991 & 1 & Primary & Melanoma & - \\
\hline
\end{tabular}


Table 2 Review of the English literature of CNS melanocytic lesions (Continued)

\begin{tabular}{|c|c|c|c|c|c|}
\hline Fish et al. & 1990 & 1 & Primary & Melanoma & - \\
\hline Salisbury et al. & 1989 & 1 & Primary & Malignant melanoma & $\begin{array}{l}\text { In association with a giant congenital } \\
\text { melanocytic naevus of 'bathing trunk' distribution }\end{array}$ \\
\hline Macfarlane et al. & 1989 & 1 & Primary & $\begin{array}{l}\text { Malignant melanoma } \\
\text { of the dura mater }\end{array}$ & - \\
\hline Iglesias-Rozas et al. & 1989 & 1 & - & $\begin{array}{l}\text { Disseminated } \\
\text { melanomatosis of the } \\
\text { CNS and other organs }\end{array}$ & - \\
\hline Larson et al. & 1987 & 5 & Primary & Melanoma & - \\
\hline Tamura et al. & 1981 & 1 & Primary & $\begin{array}{l}\text { Leptomeningeal } \\
\text { malignant melanoma }\end{array}$ & $\begin{array}{l}\text { Originated from the basal aspect of the brain. } \\
\text { The tumor showed not only spinal meningeal } \\
\text { dissemination but also infiltration into the } \\
\text { petrous bone and along the trigeminal nerve till } \\
\text { it reached the submucosal tissue of epipharynx. }\end{array}$ \\
\hline Pasquier et al. & 1978 & 1 & primary & Melanoma & With multiple metastases in the liver \\
\hline Hayward & 1976 & 27 & 20 Metastatic, 6 Primary & Malignant melanoma & - \\
\hline Kaplan et al. & 1975 & 1 & Primary & $\begin{array}{l}\text { Neurocutaneous } \\
\text { melanosis with } \\
\text { malignant } \\
\text { leptomeningeal } \\
\text { melanoma }\end{array}$ & - \\
\hline Enriquez et al. & 1973 & 1 & Primary & Malignant melanoma & $\begin{array}{l}\text { Pineal involvement in a patient with nevus of ota } \\
\text { and multiple pigmented skin nevi. }\end{array}$ \\
\hline Bergdahl et al. & 1972 & 10 & Primary & Malignant melanoma & - \\
\hline
\end{tabular}

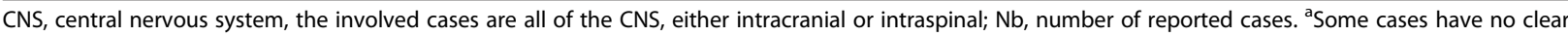
evidence to be defined as primary or metastatic tumor.

Table 3 Review of the literature of CNS amelanotic melanoma

\begin{tabular}{|c|c|c|c|c|c|}
\hline Author & Year & $\mathrm{Nb}$ & Primary/metastatic ${ }^{a}$ & Diagnosis & Other $^{b}$ \\
\hline \multirow[t]{2}{*}{ Schulz et al. [6] } & 2012 & 1 & Primary & Malignant amelanotic melanomas & (in German) \\
\hline & & & & & $\begin{array}{l}\text { Combined multiple intracranial and intraspinal } \\
\text { primary malignant amelanotic melanomas }\end{array}$ \\
\hline Cemil et al. [7] & 2008 & 1 & Metastatic & Amelanotic melanoma & - \\
\hline Karakis et al. [8] & 2007 & 1 & Metastatic & Amelanotic melanoma & - \\
\hline Jacob et al. [9] & 2006 & 1 & - & Amelanotic melanoma? & - \\
\hline Li et al. [10] & 2004 & 1 & - & Amelanotic melanoma? & (in Chinese) \\
\hline Ogawa et al. [11] & 2003 & 1 & Metastatic & Amelanotic melanoma & - \\
\hline Shields et al. [12] & 2002 & 1 & Metastatic & Amelanotic melanoma & - \\
\hline Isiklar et al. [13] & 1995 & 16 & Metastatic & Amelanotic melanoma & - \\
\hline Schadendorf et al. [14] & 1993 & 1 & - & Amelanotic malignant melanoma & - \\
\hline Takahashi et al. [15] & 1990 & 1 & Metastatic & Amelanotic melanoma & (in Japanase) \\
\hline Krüger et al. [16] & 1987 & 1 & Metastatic & Amelanotic melanoma & Associated with a congenital nevus of Ota \\
\hline \multirow[t]{2}{*}{ Sunada et al. [17] } & 1986 & 1 & Unknown origin & Amelanotic melanoma & (in Japanase) \\
\hline & & & & & $\begin{array}{l}\text { Out of review of primary uveal melanoma } \\
2365 \text { patients }\end{array}$ \\
\hline Wagner et al. [18] & 1981 & 1 & - & Amelanotic melanoma & Amelanotic melanoma of the lung and brain \\
\hline Schuknecht et al. [5] & 1990 & 2 & Primary & $\begin{array}{l}\text { Meningeal amelanotic } \\
\text { malignant melanoma }\end{array}$ & - \\
\hline
\end{tabular}


lesions of our department since 2008. The cases diagnosed earlier are not included because of the controversial diagnosis criterion before the 2007 WHO classification which are widely adopted. The location involves all the CNS, from supratentorial to intraspinal region. Due to the unspecific resemblance, there were only few cases which were diagnosed before surgery, and the differentiations were quite variable. The most common differentiations are tumors of the meninges, which belong to the same group of the melanocytic lesions, such as meningioma and the mesenchymal tumors. The hematopoietic neoplasms, cavernous hemangioma, and even the cystic lesions are also involved especially when there are hemorrhage, cystic changes, or necrosis, and so on. One of them was suspected as amelanotic melanoma. Our case is the second one with definite diagnosis of amelanotic melanoma. The clinical characteristics of amelanotic melanoma are similar to other melanocytic lesions, with the neuroimaging performance as the major difference. Also, during the operation, the amelanotic melanoma appears more pale white, and the microscopic examination reviews the lacking of melanin. As the overall examinations were all negative, the primary intracranial amelanotic melanoma was confirmed.

The prognosis of amelanotic melanoma is not quite different from other CNS melanoma. Melanocytoma lacks anaplastic features, but a few undergo local recurrences. Intermediate grade melanocytic tumors typically invade the CNS. A rare example of malignant transformation of a melanocytoma has been reported. Malignant melanoma is highly aggressive and radioresistant, has poor prognosis, and prone to metastasize. The prognosis of diffuse melanosis is poor even in the absence of histologic malignancy. The prognosis of the primary CNS melanocytic lesions appears to be better than metastatic examples. For our case of primary intracranial amelanotic melanoma, total resection was achieved as well as excessive removal of invaded cranial bone and adjacent meninges. The experience of postoperative adjuvant therapy is quite poor. We adopted the radiotherapy and chemotherapy regimen of concomitant stereotactic radiosurgery + ipilimumab, referring to the NCCN guidelines for melanoma (2.2015 version). With adjuvant radiotherapy and chemotherapy, the patient is tumor-free 5 months later and is still under follow-up.

\section{Conclusions}

CNS amelanotic melanoma is quite rare. The clinical characteristics are similar to other melanocytic lesions, with the neuroimaging performance as the major difference. The prognosis of amelanotic melanoma is not quite different from other CNS melanoma and appears to be better than the metastatic cases, particularly if localized and complete resection is possible.

\section{Consent}

Written informed consent was obtained from the patient for the publication of this case presentation and accompanying images. A copy of the written consent is available for the review by the Editor of this journal.

\section{Competing interests}

The authors declare that they have no competing interests.

\section{Authors' contributions}

Professors SW and ZZ were in charge of the treatment of the patient and performed the operation. JM and SL took part in the treatment, assembled related information, and drafted the article. XC contributed a lot in some critical work, including pathology analysis. All authors read and approved the final manuscript.

\section{Acknowledgements}

This work was supported by the Vascular and Gerontic Tumor Group of the Neurosurgery Department, the Radioimaging Department, and the Neuro-pathology Department of Beijing Tiantan Hospital.

Received: 29 December 2014 Accepted: 28 April 2015

Published online: 12 May 2015

\section{References}

1. Isiklar I, Leedsne NE, Fuller GN, Kumar AJ. Intraeranial metastatic melanoma: correlation between MR imaging characteristics and melanin content. AJR. 1995;165(6):1503-12.

2. Gaviani P, Mullins ME, Braqa TA, Hedley-Whyte ET, Halpern EF, Schaefer PS, et al. Improved detection of metastatic melanoma by T2-weighted imaging. AJNR. 2006:27(3):605-8

3. Savitz MH. Primary melanoma. J Neurosurg. 1999;90(3):609-10.

4. Winkelman MD, Adelstein DJ, Karlins NL. Intramedullary spinal cord metastasis. Diagnostic and therapeutic considerations. Arch Neurol. 1987;44(5):526-31.

5. Schuknecht B, Müller J, Nadjmi M. Malignant melanoma of the meninges MR and CT diagnosis. [Article in German] Rofo. 1990;152(1):80-6.

6. Schulz C, Waldeck S. Primary amelanotic meningeal melanomatosis. [Article in German] Fortschr Neurol Psychiatr. 2012;80(7):402-6.

7. Cemil B, Emmez H, Oztanir N, Tokgoz N, Dogulu F. A cystic amelanotic melanoma metastasis to the brain: case report. Neurocirugia (Astur). 2008;19(4):365-7.

8. Karakis I, McGeeney B, Demierre MF, Thiele JJ, Wolpowitz D, Bhawan J. Acquired hypopigmentation (leukoderma) as a presenting feature of metastatic amelanotic melanoma with brain involvement. Arch Neurol. 2007:64(12):1786-7.

9. Jacob S, Pye E, Hbahbih M, Messios N, Rajabally YA. Rapidly progressive bilateral ophthalmoplegia and enlarging sellar mass caused by amelanotic melanoma. J Neuroophthalmol. 2006;26(1):49-50.

10. Li Y, Wang S, Zhao JZ. Clinical manifestations and treatment of melanoma of the central nervous system: analysis of 15 cases. [Article in Chinese] Zhonghua Yi Xue Za Zhi. 2004;84(2):134-7.

11. Ogawa R, Aoki R, Hyakusoku H. A rare case of intracranial metastatic amelanotic melanoma with cyst. J Clin Pathol. 2003:56(7):548-51.

12. Shields JA, Perez N, Shields CL, Foxman S, Foxman B. Simultaneous choroidal and brain metastasis as initial manifestations of lung cancer. Ophthalmic Surg Lasers. 2002;33(4):323-5.

13. Isiklar I, Leeds NE, Fuller GN, Kumar AJ. Intracranial metastatic melanoma: correlation between MR imaging characteristics and melanin content. AJR Am J Roentgenol. 1995;165(6):1503-12.

14. Schadendorf D, Haas N, Worm M, Ostmeier H, Kohlmus C, Gottschalk J, et al Amelanotic malignant melanoma presenting as malignant schwannoma. $\mathrm{Br}$ J Dermatol. 1993;129(5):609-14.

15. Takahashi I, Sugimoto S, Nunomura M, Takahashi A, Aida T, Katoh T, et al. A case of cystic metastatic intracranial amelanotic melanoma-analysis of findings in CT and MRI. [Article in Japanese]. No To Shinkei. 1990:42(11):1031-4.

16. Krüger J, Hartmann V. Brain metastases of an amelanotic melanoma as the primary manifestation in a 15-year old boy. Anticancer Res. 1987;7(3 Pt B):437-9.

17. Sunada S, Date $H$, Satoh M, Iwase H. A case of intracranial amelanotic melanoma. [Article in Japanese]. No To Shinkei. 1986:38(2):201-5.

18. Wagner Jr RF, Gerard G, Sciubba JJ. Amelanotic melanoma of the lung and brain with fenestrated intrinsic tumor capillaries. Surg Neurol. 1981:15(5):384-8. 